\title{
Distribution and Source of Pb in Urban Topsoil
}

\author{
Yuhu Luo ${ }^{1,2,3,4, *}$, Nan $\mathrm{Lu}^{1,2,3,4}$ \\ ${ }^{1}$ Shaanxi Provincial Land Engineering Construction Group Co., Ltd., Xi'an 710075, China \\ ${ }^{2}$ Institute of Land Engineering and Technology, Shaanxi Provincial Land Engineering Construction \\ Group Co., Ltd., Xi' an 710075, China \\ ${ }^{3}$ Key Laboratory of Degraded and Unused Land Consolidation Engineering, the Ministry of Natural \\ Resources, Xi'an 710075, China \\ ${ }^{4}$ Shaanxi Provincial Land Consolidation Engineering Technology Research Center, Xi'an 710075, \\ China
}

\begin{abstract}
In the process of industrialization and urbanization, human activities have caused more and more heavy metal lead to enter the surface soil, causing harm to the health of residents. Analysis of the status of lead pollution in urban surface soils in China found that lead pollution in most cities currently exceeds regional background values. The sources of heavy metals in cities mainly include transportation, industrial emissions, and human activities. At present, the methods for determining sources include three methods: multivariate statistical analysis, geographic information systems, and isotope tracing.
\end{abstract}

Keywords: Pb, Urban Topsoil, Distribution

\section{Introduction}

Urban soil refers to soil that is strongly affected by human activities in urban and suburban areas. It is an organic part of the urban ecological environment system and is of great significance to the sustainable development of the city. As a component of the earth's soil circle, urban soil is the source and sink of urban pollutants, which is related to the quality of urban ecological environment and human health [1-2]. From the perspective of distribution area, man-made action mode, action intensity, and formation process, urban soil is obviously different from agricultural soil, and has the characteristics of man-made enrichment of heavy metals.

Lead and its compounds are non-degradable environmental pollutants with stable properties. They can flow into the environment in large quantities through waste water, waste gas, and waste residues, resulting in pollution and endangering human health. Lead damage to the body is multi-systemic and multi-organic, including the toxic effects on the bone marrow hematopoietic system, immune system, nervous system, digestive system and other systems. As a central nervous system poison, lead is more harmful to children's health and intelligence [3]. Although China has implemented lead-free gasoline in 2000, there is still a serious accumulation of $\mathrm{Pb}$ in urban soil, and the situation of $\mathrm{Pb}$ pollution in urban

* Corresponding author e-mail: huyu_luo@163.com 
soil is still very severe. Environmental problems have always been an important factor that plagued human sustainable development. Especially in densely populated urban areas, environmental problems are even more serious. In recent years, with the continuous increase of the urban population, the pressure on urban environmental protection is increasing, and various environmental problems have appeared one after another, which has seriously affected human physical and mental health. Especially with the acceleration of China's urbanization process, the urban population has increased dramatically, and the use of corresponding infrastructure, transportation, and various lead-containing building materials has increased, which has increased the possibility of urban soils being contaminated by lead heavy metals. According to previous survey results, lead in urban surface dust is at a high ecological risk level, and most of this lead is related to human activities [4]. Therefore, in order to prevent lead pollution from causing serious harm to the health and economic development of urban residents, it is necessary to analyze the source and diffusion law of lead to find the source of pollution and control the pollution from the source.

\section{Analysis of lead pollution in urban soil}

Lead can easily enter the urban topsoil through transportation, industrial emissions, and atmospheric sedimentation, causing the accumulation and pollution of heavy metals in urban surface dust, which seriously threatens the health of urban residents. The analysis of urban soil lead content and its pollution sources found that industrial activities, urban transportation, and human activities are the main sources of soil lead pollution. Industrial pollution is mainly soil pollution caused by dry and wet sedimentation such as smoke or dust emitted by industrial enterprises in urban areas; traffic pollution is mainly exhaust gases emitted by motor vehicles and vehicle construction wear and tear carried into the soil through atmospheric diffusion and sedimentation. In addition, some studies have shown that the use of leaded gasoline also contributes to soil lead pollution. Although unleaded gasoline has been widely used in China, the lead that entered the soil when leaded gasoline was originally used still accumulates in the soil. According to the results of previous studies, the content of lead in the soil in many cities across the country is significantly higher than the background value, and some cities have a pollution index greater than 1(Table 1). Therefore, urban environment lead pollution, which is closely related to human health, has become one of the hot topics of research. It is urgent to judge the source of lead pollution, and then prevent and control it from its root cause.

Table 1. Pb content in major Chinese cities [5].

\begin{tabular}{|c|c|c|c|c|c|c|c|}
\hline City & Beijing & Shenyang & Jilin & Shanghai & Nanjing & Hangzhou & Guangzhou \\
\hline Average value & 39.5 & 75.3 & 34.7 & 127.6 & 107.3 & 114.5 & 121.6 \\
\hline Background values & 25.4 & 22.2 & 12 & 25 & 23.4 & 23.7 & 47.1 \\
\hline Pollution index & 0.4 & 0.75 & 0.35 & 1.28 & 1.07 & 1.15 & 1.22 \\
\hline
\end{tabular}

\section{Source analysis of heavy metal lead}

The sources of lead in urban soils include both natural and anthropogenic sources. Generally, natural sources are few and most are the result of anthropogenic sources. The source of heavy metal $\mathrm{Pb}$ is mainly determined by multivariate statistical analysis, geographic information system (GIS), and isotope tracer. 


\subsection{Multivariate statistical analysis}

Multivariate statistical analysis is an effective method for determining common models in data distribution, and has been widely used for traceability of heavy metals in sediments, water bodies, and dust. Common methods include: cluster analysis, principal component analysis, and factor analysis. In practical applications, several methods need to be used in combination to achieve good results. For example, correlation analysis can improve and support the results of cluster analysis or principal component analysis, cluster analysis can verify the results of principal component analysis, principal component analysis can quantify the results of cluster analysis, and use the results generated by principal component analysis It is linearly independent and can overcome the problem of collinear variables in regression analysis.

\subsection{GIS technology}

GIS is an automated system that collects, stores, retrieves, analyzes, and displays spatial data. Because the distribution of heavy metals has spatial attributes, GIS can be used to collect and analyze its spatial attribute data to discover the characteristics of its spatial distribution. At the same time, the natural and social environmental data in the region are combined to analyze the reasons for the differences in the distribution of heavy metals and finally determine the source.

\subsection{Isotope tracer technology}

There are four stable isotopes of lead in nature: ${ }^{208} \mathrm{~Pb},{ }^{207} \mathrm{~Pb},{ }^{206} \mathrm{~Pb}$, and ${ }^{204} \mathrm{~Pb}$. Among them, ${ }^{208} \mathrm{~Pb},{ }^{207} \mathrm{~Pb}$, and ${ }^{206} \mathrm{~Pb}$ are the final products of decay of ${ }^{232} \mathrm{Th},{ }^{235} \mathrm{U}$, and ${ }^{238} \mathrm{U}$, respectively, so their abundances increase with time. Since ${ }^{204} \mathrm{~Pb}$ has not been found to have a radioactive parent, it can be considered that its abundance remains unchanged [6]. Due to the large mass number of lead isotopes, the relative mass difference between different isotopes is small, and almost no isotope fractionation occurs. Therefore, the isotopic composition of lead generally does not change with the changes in the physical and chemical conditions of the system. Its isotopic composition mainly depends on the initial lead, uranium and thorium content of the source area and the time of the radioactive uranium/thorium decay reaction, and is basically not affected by the geochemical environment in which it was formed [7-8]. Therefore, in the field of environmental pollution research, the special "fingerprint" feature of lead isotopes is often used to trace the source of lead pollution. At present, in the traceability of lead isotopes, the four isotope ratios of $206 \mathrm{~Pb} / 204 \mathrm{~Pb}, 207 \mathrm{~Pb} / 204 \mathrm{~Pb}, 208 \mathrm{~Pb} / 204 \mathrm{~Pb}$, and $206 \mathrm{~Pb} / 207 \mathrm{~Pb}$ are mainly used for discussion and analysis, to determine their source and diffusion pathway. Among the four isotopes of lead, the abundance of ${ }^{204} \mathrm{~Pb}$ is high, but the measurement accuracy is low. The standard deviation of the ${ }^{206} \mathrm{~Pb} /{ }^{207} \mathrm{~Pb}$ and ${ }^{208} \mathrm{~Pb} /{ }^{207} \mathrm{~Pb}$ tests is low, and mineralogical changes are not easy to occur. Therefore, it is often used to determine the source of lead [9]. Generally, in the natural background, ${ }^{206} \mathrm{~Pb} /{ }^{207} \mathrm{~Pb}$ is larger and its value is greater than 1.20; while the lead caused by man-made causes is slightly smaller, which is generally $0.96-1.20$. Based on this, the source of pollution in the study area can be inferred [10]. Early lead isotope techniques were applied to the study of atmospheric particulate sources of lead pollution, and have since gradually expanded to soils and sediments. Foreign scholars have conducted a lot of research through lead isotope tracer technology, and as a result, most of the lead pollution on the surface is related to industrial activities [11]. The isotope tracing technology started late in China. From the research results, the sources of lead pollution in soils in different regions behave differently. Forest soil lead 
pollution mainly comes from coal combustion and industrial emissions [12]; in mineral distribution areas, soil lead pollution mainly comes from ore [13]; urban soil lead pollution mainly comes from automobile exhaust pollution, industrial coal combustion emissions and construction Dust and other pollution results [14].

\section{Conclusion}

With the acceleration of urbanization, urban surface soils are increasingly harmed by heavy metal lead pollution. The main sources of lead include natural and anthropogenic sources, and anthropogenic sources are its main aspects. Anthropogenic sources include transportation, industry Emissions and human daily production activities. At present, the lead in surface soils of some major cities in China is generally higher than the background value. Therefore, it is urgent to judge the source of lead to effectively reduce lead pollution.

\section{Acknowledgments}

This work was financially supported by the Research Project of Shaanxi Provincial Land Engineering Construction Group in China (DJNY2019-18).

\section{References}

1. PATERSON E, SANK M, CLARK L. Urban soils as pollutant sinks-a case study form Aberdeen, Scotland, Applied Geochemistry. 11(1996) 129-131.

2. Lu Ying, Gong Zitong, Zhang Ganlin. Characteristics and Management of Urban Soils, Soil and Environmental Sciences. 11(2002) 206-209.

3. Committee on Measuring Lead in Critical Populations. Measuring Lead exposure in inants, children and other sensitive population[M]. Washington DC:National Academy Press, 1993:1-72.

4. Wang Li, Wang Lijun, Shi Xingmin, et al. Distribution, Sources and Potential Ecological Risk of Heavy Metals in Surface Dusts from Urban areas of Xi'an City, Environmental Science and Technology. 40 (2017) 180-187.

5. Gao Feixia, Zou Tiansen, Zhang Jinliang, et al. Lead Concentration in Urban Soils of China, Urban Environment and Urban Ecology. 28 (2015) 1-5.

6. Yu Ruilian, Hu Gongren, Yuan Xing, et al. Application of isotope tracer technology to trace source pollution of heavy metals in sediments [J]. Earth and environment, 2008, 36 (3): 245-250.

7. Komárek M, Ettler V, Chrastný V, et al. Lead isotopes in environmental sciences: A review, Environment International. 34 (2008) 562-577.

8. Cheng $\mathrm{H} \mathrm{F}, \mathrm{Hu} \mathrm{Y}$ A. Lead $(\mathrm{Pb})$ isotopic fingerprinting and its applications in lead pollution studies in China: A review, Environmental Pollution. 158 (2010) 1-13.

9. Roussiez V, Ludwig W, Prodst J, et al. Background levels of heavy metals in surficial sediments of the Gulf of Lions (NW Mediterranean): An approach based on $133 \mathrm{Cs}$ normalization and lead isotope measurements, Environmental Pollution. 138 (2005) 167-177.

10. Sturges W T, Barrie L A. Lead ${ }^{206 / 207}$ isotope ratios in the atmosphere of North America as traces of US and Canadian emissions, Nature. 329 (1987) 144-146.

11. Jaime E, Thomas J W, George D K, et al. Isotope record of anthropogenic lead 
pollution in lake sediments of Florida, USA, Journal of Paleolimnology. 49 (2013) 237-252.

12. Kuang Y W, Zhu X M, Xi D, et al. Distribution of anthropogenic lead estimated by $\mathrm{Pb}$ isotopic composition in the upper layers of soil from a mixed forest at Dinghushan,southern China, Journal of Soils and Sediments. 13 (2013) 394-402.

13. Chu Binbin, Luo Liqiang, Wang Xiaofang, et al. Lead isotopes as tracers in the Qixiashang lead-zinc mineing area, Nanjing, Acta Geoscientica Sinica. 33 (2012) 209-215.

14. Yang Zhongping, Lu Wenxi, Xin Xin, et al. Lead isotope signatures and source identification in urban soil of Changchun city, Journal of Jilin University(Earth Science Edition). 38 (2008) 663-669. 